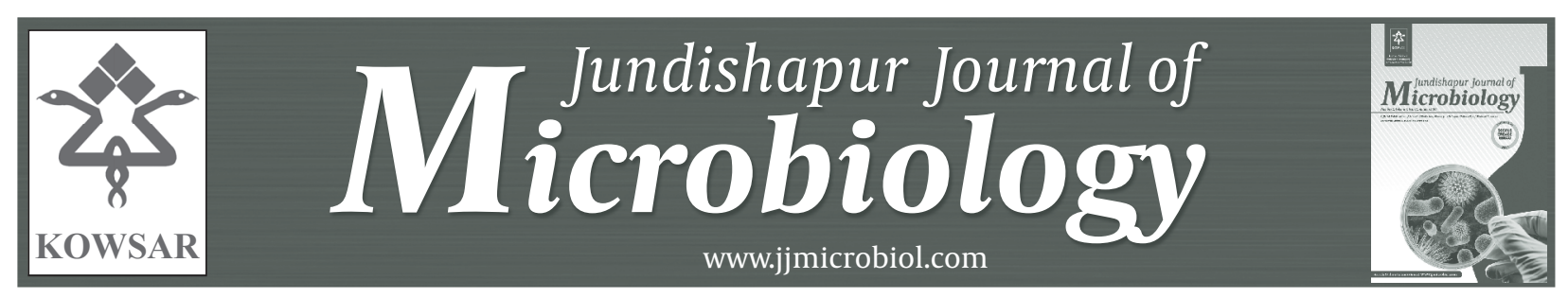

\title{
Relative Frequency of Echovirus 30 in Patients Suffering From Enterovirus Meningitis in Ahvaz
}

\author{
Mojtaba Rasti ${ }^{1,2}$, Ali Samarbaf-Zadeh ${ }^{1,3^{*}}$, Manoochehr Makvandi ${ }^{1,2,3}$, Niloofar Neisi ${ }^{1,2}$, Ah- \\ mad Shamsizadeh $^{4}$ \\ ${ }^{1}$ Department of Medical Virology, School of Medicine, Ahvaz Jundishapur University of Medical Science, Ahvaz, IR Iran \\ ${ }^{2}$ Research Institute for Infectious Diseases of Digestive System, Ahvaz Jundishapur University of Medical Science, Ahvaz, IR Iran \\ ${ }^{3}$ Infectious and Tropical Disease Research Center, Ahvaz Jundishapur University of Medical Science, Ahvaz, IR Iran \\ ${ }^{4}$ Department of Pediatrics, Ahvaz Aboozar Hospital, Ahvaz Jundishapur University of Medical Science, Ahvaz, IR Iran \\ * Corresponding author: Ali Samarbaf-Zadeh, Department of Medical Microbiology, School of Medicine, Ahvaz Jundishapur University of Medical Science, \\ Ahvaz, IR Iran.Tel.: +98-6113354389, Fax:+98-6113361544, E-mail: alirezasamarbaf_78@hotmail.com
}

\begin{abstract}
A B S T R A C T
Background: Human enteroviruses are members of Picornaviridae family; they are non-enveloped, icosahedral viruses with positive RNA as genome. Echovirus 30 is an important member of enteroviruses that is recognized in outbreaks of enterovirus meningitis. objectives: The aim of this study was to determine relative frequency of echovirus 30 as an important agent of aseptic meningitis among children referred to Aboozar hospital, Ahvaz, Iran.

Patients and Methods: 34 cerebrospinal fluid samples from patients with enterovirus aseptic meningitis, negative bacterial culture, WBC (white blood cell) count $>5 \times 106 / \mathrm{mm} 3$, and aseptic meningitis symptoms were entered in the study. These samples were collected in a year between May 2010 and May 2011. RNA of enteroviruses were extracted and investigated for echovirus 30 infection with RT-PCR (reverse transcription polymerase chain reaction) test. Samples also were cultured in RD (rhabdomyosarcoma) cell and positive results were approved by RT-PCR test with enterovirus specific primers. To recognize PCR-product, 440 bp RT-PCR product was sequenced and phylogenic tree was drawn based on Neighbor Joining method with 1000 replication bootstrap.

Results: Echovirus 30 infection was not detected in any case. Just one CSF sample grew in RD cell culture. This sample was approved by RT-PCR and sequencing. Positive sample was recognized as coxsackie virus B3.

Conclusions: There was no echovirus 30 in Ahvaz because of diverse nature of enteroviruses and several serotypes with various distribution patterns in different geographical regions, and the fact that echovirus 30 is mostly detected in outbreaks rather than endemism. Coxsackie virus B3 was responsible for aseptic meningitis of a child in this study. Based on another study conducted in Tehran, it seems that Coxsackie B viruses are among current agents causing enterovirus aseptic meningitis in Iran. Of course we need to conduct more studies in Ahvaz and other parts of the country to approve this hypothesis.
\end{abstract}

Keywords: Enterovirus B, Human; Meningitis, Aseptic; Reverse Transcriptase Polymerase Chain Reaction; Cell Culture Techniques

Copyright @ 2013, Kowsar Corp.; Published by Kowsar Corp.

-Article type: Research Article; Received: 26 Mar 2012, Revised: 22 May 2012, Accepted: 20 Jun 2012; DOI: 10.5812/jjm.4972

-Implication for health policy/practice/research/medical education:

This article will help clinicians and environmental hygiene policy makers for better understanding of enteroviruses epidemiology in Ahvaz.

Please cite this paper as:

Rasti M, Samarbaf-Zadeh AR, Makvandi M, Neisi N, Shamsizadeh A. Relative Frequency of Echovirus 30 in Patients Suffering From Enterovirus Meningitis in Ahvaz.Jundishapur J Microbiol. 2013;6(2):157-161. DOI: 10.5812/jjm.4972

(C) 2013 Ahvaz Jundishapur University of Medical Sciences; Published by Kowsar Corp.

This is an Open Access article distributed under the terms of the Creative Commons Attribution License (http://creativecommons.org/licenses/by/3.0), which permits unrestricted use, distribution, and reproduction in any medium, provided the original work is properly cited. 


\section{Background}

Enteroviruses are small, non-enveloped viruses with icosahedral symmetry. They are members of Picornaviridae family that cause wide spectrum of diseases such as respiratory infection, gastroenteritis, sepsis, myocarditis, and meningitis (1). They have a single stranded positive sense RNA as genome with only one ORF (open reading frame). The genome consists of three parts as P1, P2, and P3. P1 encodes capsid protein and two other parts encode non-structural proteins such as proteases.

Enteroviruses are divided in four sub-groups including human enterovirus A (HEV A), human enterovirus B (HEV $B)$, human enterovirus $\mathrm{C}$ (HEV C), and human enterovirus $\mathrm{D}$ (HEV D) (2, 3). Aseptic meningitis is one of the most important diseases related to enteroviruses that are responsible for about 80 to 90 percent of viral meningitis over the world. The disease is recognized by symptoms such as fever, volve children and young adults. In children and newborns, infection can spread through the body and cause some serious diseases like hepatitis and myocarditis. These viruses are transmitted via oral-fecal route and mostly seen in fall and summer at temperate areas (4).

Echovirus 30 as a member of enteroviruses was reported from some countries such as Kuwait, Turkey, Brazil, and Korea $(2,5-7)$. Cell culture was the gold standard and classical diagnostic method for detection and isolation of enteroviruses but as this method is very time consuming and needs much facilities, after the advent of molecular techniques such as PCR most studies are performed based on these techniques (8).

\section{Objectives}

In this survey, 34 enterovirus positive cerebrospinal fluid (CSF) samples were collected during one year and investigated by RT-PCR(reverse transcription polymerase chain reaction), cell culture, and sequencing to determine relative frequency of echovirus 30 as an important agent of aseptic meningitis. headache, neck stiffness, and photophobia that mostly in-

\section{Patients and Methods}

\subsection{Patients}

In this study, we investigated 34 CSF samples collected between May 2010 and May 2011 from 57suspected patients less than 14 years old (average: $1.58 \pm 2.25$ years old) with aseptic meningitis who were referred to Aboozar hospital, Ahvaz, Iran. The sample collection was performed with patient's consent. These 34 cases suffered from enterovirus meningitis already approved by RT-PCR test in previous study (9). Thirty four patients with symptoms of aseptic meningitis, negative bacterial culture, WBC count $>5 \times 106 /$ $\mathrm{mm} 3$, and positive RT-PCR test for enteroviruses with pan enterovirus primers were entered in the study. Most of the cases were under 2 years old (about $80 \%$ ); also a 2-day-old patient who suffered from heart attack was recognized among the patients. Most cases occurred in winter and fall respectively with no significance relationship between spring, winter, and fall ( $\mathrm{P}>0.05)$; these information were already mentioned in previous study (9). Clinical symptoms and laboratory characteristics of patient's CSF were recorded and shown in Table 1 and Table 2 , respectively.

Table 1. Symptoms Were Observed in All Patients with Aseptic Meningitis (57 Cases) and Patients of which with Enterovirus Meningitis (34 Cases).

\begin{tabular}{|lll}
\hline Symptoms & Total, \% & Enterovirus, \% \\
\hline Fever & 82 & 78 \\
Seizures & 46 & 44 \\
\hline Vomiting & 46 & 44 \\
\hline Fatigue & 28 & 16 \\
\hline Diarrhea & 28 & 22 \\
\hline Neck stiffness & 14 & 11 \\
\hline Hallucination & 18 & 16 \\
\hline Flu like symptom & 11 & - \\
\hline Anorexia & 18 & 22 \\
\hline Headache & 11 & 11 \\
\hline
\end{tabular}

Table 2. Characteristics of CSF in Different Age Groups. Numbers in Parenthesis Indicate the Range and Outer Numbers Indicate the Average.

\begin{tabular}{lllll}
\hline CSF Characteristics & $<$ 1 year & 1 to 2 years & > 2 years & Average \\
\hline WBC Count $(/ \mathbf{m m} \mathbf{3})$ & $36(1-172)$ & $183(5-540)$ & $71(7-125)$ & $76(1-540)$ \\
Lymphocytes & $27(1-137)$ & $150(4-459)$ & $43(2-85)$ & $59(1-459)$ \\
Neutrophils & $8(0-35)$ & $33(0-81)$ & $28(5-57)$ & $17(0-81)$ \\
Protein, $\mathbf{m g} / \mathbf{d L}$ & $40(12-278)$ & $42(17-105)$ & $18(12-24)$ & $37(12-278)$ \\
Glucose, $\mathbf{m g} / \mathbf{d L}$ & $97(15-455)$ & $70(25-135)$ & $79(58-95)$ & $88(15-455)$ \\
\hline
\end{tabular}

\subsection{Virus Extraction and cDNA Synthesis}

Viral RNA was extracted from CSF samples with a high pure viral nucleic acid kit (Roche Diagnostics, Indianapolis, USA) according to manufacturer's instruction. cDNA was synthesized using a cDNA synthesize kit(Vivantis, Malaysia)

in two steps according to manufacturer's instruction. In the first step, a mixture of $1 \mu \mathrm{L}$ random primer $(2.5 \mathrm{ng} / \mu \mathrm{L}), 1 \mu \mathrm{L}$

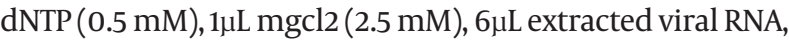
and $1 \mu \mathrm{L}$ of diethylpyrocarbonate (DEPC) water was prepared in a $10 \mu \mathrm{L}$ volume and incubated at $65^{\circ} \mathrm{C}$ for 5 minutes and 
chilled on ice for 2 minutes, respectively. In the second step, a mixture of $2 \mu \mathrm{L} 10 \mathrm{X}$ buffer M-MuLV, 0.5 $\mu \mathrm{L}$ M-MuLV reverse transcriptase $(100 \mathrm{U} / \mu \mathrm{L})$, and $0.5 \mu \mathrm{L}$ RNase inhibitor $(20 \mathrm{U} / \mu \mathrm{L})$ in $7 \mu \mathrm{L}$ of DEPC water was prepared and added to the first mixture, mixed, and then incubated in $42^{\circ} \mathrm{C}$ for 60 minutes. The reactions were incubated at $85^{\circ} \mathrm{C}$ for 5 minutes to terminate the reaction.

\subsection{RT-PCR Amplification for Echo 30 Detection}

CSF samples of 34 patients with enterovirus meningitis were investigated for echovirus 30 by RT-PCR. The specific primers for echovirus 30 consisted of 120 S (GACCCIGARIRIGCIYTNAA) (VP1, 4-23) and 47 A (TKIACRTGICKIGTYTGCAT) (VP1, 143-162) with the PCR product of $158 \mathrm{bp}$ (9). PCR amplification were prepared in a final volume of $25 \mu \mathrm{L}$ containing $5 \mu \mathrm{L}$ of cDNA, $2.5 \mu \mathrm{L}$ 10x viBuffer, $0.5 \mu \mathrm{L}$ dNTP $(10$ $\mathrm{mM}), 0.125 \mu \mathrm{L}$ taq polymerase (0.625 unit) , $1.5 \mathrm{mM} \mathrm{MgCl}$, $0.75 \mu \mathrm{L}$ from each primer $(0.3 \mu \mathrm{M})$, and water up to $25 \mu \mathrm{L}$. The cycling was programmed as:; incubation at $94^{\circ} \mathrm{C}$ for 5 minutes and 35 cycles with denaturation at $94^{\circ} \mathrm{C}$ for $30 \mathrm{~s}$, annealing at $52^{\circ} \mathrm{C}$ for 30 s, extension at $72^{\circ} \mathrm{C}$ for $30 \mathrm{~s}$, and final extension at $72^{\circ} \mathrm{C}$ for 5 minutes . $10 \mu \mathrm{L}$ of PCR product was mixed with $6 x$ loading dye and loaded onto $2 \%$ $\mathrm{w} / \mathrm{v}$ agarose gel. After the electrophoresis (100 volts for 50 minutes, $0.5 \mathrm{x}$ TBE buffer) the gel was stained in ethidium bromide $(0.5 \mu \mathrm{g} / \mathrm{mL})$, the amplicon was visualized, and its size was determined using UV trans-illuminator (Lambert, France) to observe 158 bp band.

\subsection{Virus Isolation}

We used cell culture to propagate the virus and increase its titer. Culture also was used to distinct between virion and defective particles. Achieving this goal, we used RD cells (rhabdomyosarcoma) isolated from a kind of malignant skeletal muscle cell. After preparation of culture tubes with 70\% to $80 \%$ confluent RD cells, about $200 \mu \mathrm{L}$ from each of 34 samples was added to each tube, incubated the tubes in an incubator with $37^{\circ} \mathrm{C}$ temperature and 5\% CO2 for one hour to attach viruses to cell receptors, and shaken the tubes gently every 15 minutes for even distribution of samples on tubes surfaces. After 1 hour, tubes were discharged, about $1 \mathrm{~mL}$ maintenance MEM media (MEM media with $2 \%$ calf serum) was added, and kept in $37^{\circ} \mathrm{C}$ incubator with $5 \% \mathrm{CO}$. Tubes were monitored daily for 7 days to observe cytopathic effect (detached cells, round cells)(9).

\subsection{Virus Extraction from the Culture}

The enterovirus RNA was extracted from supernatant of cultures with Tripure reagent (Roche Diagnostics, Indianapolis, USA) and chloroform. Isopropanol and ethanol were used to precipitate and sediment RNA which was hydrated with $50 \mu \mathrm{L}$ of DEPC water; extraction procedure was performed according to manufacturer's instruction and cDNA was synthesized as mentioned before.

\subsection{RT-PCR Amplification for Enterovirus Detection and Sequencing}

cDNA was synthesized from Cell culture supernatant extract and investigated by RT-PCR with pan enterovirus primers. The specific primers were : EV-1: CAAGCACTTCTGTTTCCCCGG, (5' UTR, 168-188) and EV-R: ATTGTCACCATAAGCAGCCA, (5' UTR, 588-606); these primers amplify an amplicon with 440 bp in length. Amplification were prepared finally in a mixture containing $5 \mu \mathrm{L}$ of cDNA, $5 \mu \mathrm{l}$ $10 x$ viBuffer, $1 \mu \mathrm{L}$ dNTP $(10 \mathrm{mM}), 0.25 \mu \mathrm{L}$ (1.25 unit) taq polymerase, $3 \mathrm{mM} \mathrm{MgCl} 2,1.5 \mu \mathrm{L}$ from each primer $(0.3 \mu \mathrm{M})$, and water up to $50 \mu \mathrm{L}(10)$. The cycling program included incubation at $94^{\circ} \mathrm{C}$ for 5 minutes and 35 cycles with denaturation at $94^{\circ} \mathrm{C}$ for $1 \mathrm{~min}$, annealing at $53^{\circ} \mathrm{C}$ for $1 \mathrm{~min}$, extension at $72^{\circ} \mathrm{C}$ for $1 \mathrm{~min}$, and final extension at $72^{\circ} \mathrm{C}$ for 5 minutes . $5 \mu \mathrm{L}$ of PCR product was mixed with $6 \mathrm{x}$ loading dye and loaded onto $2 \% \mathrm{w} / \mathrm{v}$ agarose gel. After the electrophoresis (100 volts for 50 minutes, 0.5x TBE buffer), the gel was stained in ethidium bromide $(0.5 \mu \mathrm{g} / \mathrm{mL})$ and amplicon was visualized using UV trans-illuminator (Lambert, France) to observe 440 bp band. PCR product was sent to Bioneer Company (Korea) for sequencing.

\subsection{Phylogenic Analysis}

440 bp sequencing result of a positive sample was entered in gene bank and compared with sequences of enterovirus strains using the Basic Local Alignment Search Tool (BLAST). Coxsackie virus B3, Jiangsu strain exhibited a high identity and query coverage with highest total score with our sequence. We prepared a database with our sequences and other coxsackie virus B3 and draw a phylogenic tree using MEGA software version 5 by Neighbor Joining method with 1000 replication bootstrap (Figure 1).

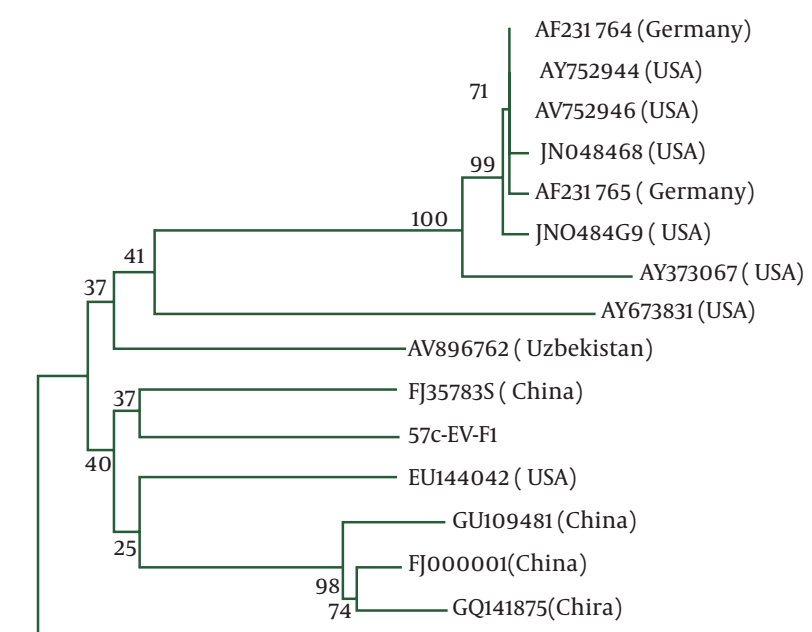

FJ859064 PV1

Figure 1. Phylogenic Tree Based on 5'UTR Sequencing with Neighbor Joining Method and 1000 Replication Bootstrap. 


\section{Results}

In this study, we investigated 34 CSF (cerebrospinal fluid) samples from patients under 14 years old with enterovirus aseptic meningitis using RT-PCR, cell culture, and sequencing tests. More frequent observable symptoms of aseptic meningitis in these patients included fever (78\%), seizures (44\%), vomiting (44\%), and other symptoms that are shown in Table 1 . Patients' CSF characteristics were also determined; in all of them lymphocytes were dominant; details are shown in Table 2 . After performing RTPCR to detect echovirus 30 among 34 CSF samples, we didn't find any positive sample.

Thirty four enterovirus positive samples were cultured in $\mathrm{RD}$ cell among them only one sample showed the growth that was approved by RT-PCR with pan enterovirus primers of 5'UTR region with 440bp amplicon (Figure 2). Positive sample in culture was sent to Bioneer Company for bidirectional sequencing; it was recognized as coxsackie virus B3. Phylogenic tree analysis of coxsackie virus B3 was drawn by Neighbor Joining method (Figure 1). Based on the tree, this virus is similar to a strain of coxsackie B3 virus from Jiangsu China.

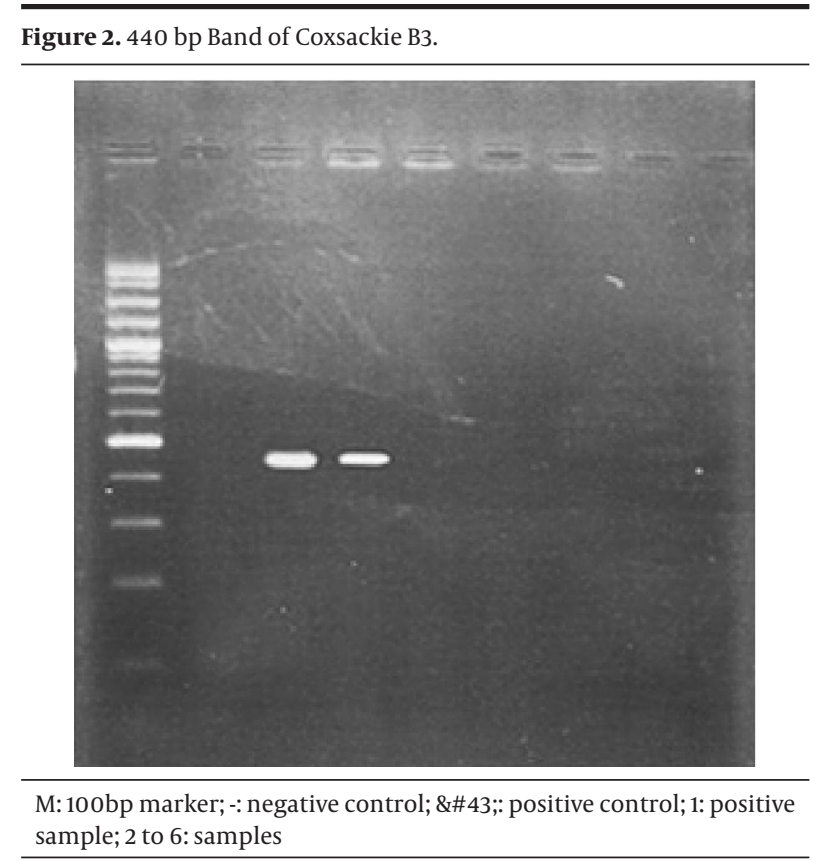

\section{Discussion}

Aseptic meningitis is one of the most prevalent infectious diseases in children and adults that is recognized by clinical symptoms such as fever, headache, neck stiffness, and photophobia $(1,3)$. Viruses are among major pathogens of aseptic meningitis and the most important genus is enterovirus. Gold standard for diagnosis of enterovirus infection is virus isolation in cell culture, but nowadays most researchers use molecular methods such as RT-PCR that is more sensitive than virus isolation (8).

We didn't detect echovirus 30 in our patients because of some essential features of enteroviruses among them it is notable that coxsackie B5 virus, echovirus type 4, 6 , 9 , and 30 are famous to create outbreaks and are associated with greater frequency of meningitis than others (7), in previous studies was done in Ahvaz, we didn't see the characteristics of an outbreak $(9,10)$. High prevalence of enteroviruses in Ahvaz $(9,10)$ is due to poor hygiene and contaminated water and therefore, we can call it as an endemic area. In such endemic area, echovirus 30 has a low chance to be a major cause of meningitis. Second reason might be attributed to different epidemiology of enteroviruses in different geographical regions and high diversity exists in human enteroviruses.

Our results are similar to two reports from Kuwait and Iran $(2,11)$. Dalwai's study from Kuwait surveyed enterovirus epidemiology in a three years period, and observed that echovirus 30 was prevalent only in the third year (2). Also, in a study performed in Tehran, Iran by Mirpour et al, echovirus 30 was not observed in patients with aseptic meningitis; all of them were found to have coxsackie B4 and B5 (11). Our results are fully similar to their survey. Decrease in positive cases in cell culture (only one sample) may have several causes. The first one returns to the culture method.

As all enteroviruses cannot be cultured using only one cell type, the method which was performed by us, therefore, we reached to a low positive result. The second reason might be attributed to the existence of antibody in CSF samples that may neutralize virus particles and prevent them to attach to the cell receptors. In different studies, researchers use different kinds of primers to amplify different regions of enterovirus genome. In some studies, VP1 region is used to sequence enteroviruses but in this region, almost all primers are degenerated because of much variety that exists in VP1 region (2); so, in other studies VP2-VP4 regions and 5'UTR region are used for sequencing $(2,12)$ in which common primers can be used better than that in VP1 region to setup a PCR reaction . The result of our sequencing was coxsackie B3 virus and based on phylogenic tree, it was similar to a strain in Jiangsu, China (10). This result is remarkable because coxsackie B3 virus is a major cause of myocarditis among enteroviruses and, as mentioned in patients section, we recognized a 2-day- old patient who suffered from heart attack.

There was no echovirus 30 in Ahvaz because of diverse nature of enteroviruses and several serotypes with various distribution patterns in different geographical regions, and the fact that echovirus 30 is mostly detected in outbreaks, rather than endemism. Coxsackie virus B3 was responsible for aseptic meningitis in a child in this study. Based on another study conducted in Tehran, Iran, it seems that coxsackie B viruses are among current agents 
causing enterovirus aseptic meningitis in Iran. Of course we need to perform more studies in Ahvaz and other parts of the country to approve this hypothesis.

\section{Acknowledgements}

The authors of this article are greatly thankful to Dr. Shohre Shahmahmoodi for providing positive enterovirus control for the study. Special gratitude also goes to all coworkers in the virology department of Ahvaz Jundishapur University of Medical Science.

\section{Financial Disclosure}

None declared.

\section{Funding/Support}

This study was supported by Research Centre for Tropical and Infectious Diseases and Vice Chancellor of Research and Technology.

\section{References}

1. Irani DN. Aseptic meningitis and viral myelitis. Neurol Clin. 2008;26(3):635-55.

2. Dalwai A, Ahmad S, Al-Nakib W. Echoviruses are a major cause of aseptic meningitis in infants and young children in Kuwait. Virol
J. 2010;7(236).

3. Lee BE, Davies HD. Aseptic meningitis. Curr Opin Infect Dis 2007;20(3):272-7.

4. Korsun N, Gyurova SN, Mladenova Z. Virological surveillance of Enteroviral infection in Bulgaria during the period 2001-2004. Biotechnol Biotechnol Eq. 2005;19:56-60.

5. Baek K, Yeo S, Lee B, Park K, Song J, Yu J, et al. pidemics of enterovirus infection in Chungnam Korea, 2008 and 2009. Virol J. 2011;8(297)

6. Machado BC, Ferreira RdS, Carmona RdCC, Timenetsky MdCST. Aseptic meningitis by echovirus 30 in São Paulo state, Brazil. Brazilian J Microbiol. 2007;38:97-103.

7. Sensoy G, Sel K, Ozkaya E, Cuhaci Cakir B, Vidinlisan S, Doganci L. Enteroviral meningitis in children in Turkey. Central Europ J Med. 2009;4(2):253-8.

8. Gomes Mde L, Ferreira LL, Gomes RH, Lamarao LM, da Silveira E, Rodrigues Lda S, et al. RT-PCR for confirmation of echovirus 30 isolated in Belem, Brazil. Braz Infect Dis. 2007;11(4):403-6.

9. Rasti M, Samarbaf-Zadeh AR, Makvandi M, Shamsi-Zadeh A. Relative Frequency of Enteroviruses in Children With Aseptic Meningitis Referred to Aboozar Hospital in Ahvaz. Jundishapur J Microbiol. 2012;5(3):456-9.

10. Sohrabi A, Samarbafzadeh AR, Makvandi M, Shamsizadeh A Shamsi Shahrabadi M. Epidemiological survey of Enteroviral meningitis in children younger than 14 years in Ahvaz. Iranian JVirol. 2007;1:26-9.

11. Mirpour MS. Serotyping of Enteroviruses, and evaluation of these rules on producing aseptic meningitis in less than 14 years children. J Sci. 2009;18:1-8.

12. Hsu BM, Chen $\mathrm{CH}$, Wan MT. Prevalence of enteroviruses in hot spring recreation areas of Taiwan. FEMS Immunol Med Microbiol. 2008;52(2):253-9. 